\title{
Korean Language Learning in Socio-educational Settings in Sydney* \\ : Motivation, Learning-Styles and Learning Experiences
}

\section{Seong-Chul Shin**}

(The University of New South Wales, UNSW)

* This is a revised version of my paper presented at the 31st Korea Grammar Education Circle Conference held on the 10th of August 2019 at Yonsei University, Seoul. ** School of Humanities and Languages, UNSW, Senior Lecturer/Assoc. Professor SEONG-CHUL SHIN is an applied linguist based at the School of Humanities and Languages, University of New South Wales, Sydney, Australia. In the capacity of senior lecturer/associate professor he conducts research in the areas of applied, educational and socio-linguistics with a particular focus on Korean as a foreign, second or heritage language, while teaching undergraduate courses and supervising postgraduate research students. His recent books include: Korean Heritage Language Maintenance, Learning and Development: Australian Practices and Perspectives (ed. 2019), Korean Language Education: Australian Practices and Perspectives (2018), and Understanding L2 Korean Learner Errors: Description, Explanations and Implications (2017). He is currently undertaking research projects on the impact of migration on minority languages and cultural identities. 


\section{ABSTRACT}

Seong-Chul Shin. 2020. Korean Language Learning in Socio-educational Settings in Sydney: Motivation, Learning-Styles and Learning Experiences. Teaching Korean as a Foreign Language, 58. 351-381. This paper presents an analysis of Korean Language Learning (KLL) conducted through socio-educational programs offered by two public organisations in Sydney. For this purpose, the study conducted a survey which investigates motivational factors, preferred learning styles and learning experiences. The study has also examined views on online Korean language learning such as perceived effectiveness, advantages and disadvantages. A total of 105 learners of Korean participated in the survey, and results are presented and interpreted under four broad subtopics: reasons for learning Korean, learning-style preferences, learning experiences and online mode of learning. The analysis reveals that social learners were very practical about their study of Korean, and they wanted to learn conversational Korean through repetition practices and enjoyable real-life language activities. Brief discussions are offered on implications. It is argued that in socio-educational language programs, more 'integrative' orientations need to be reflected, and practical goals related to putting the language to some types of use should be emphasised. It is also argued that more governmental and institutional efforts should be made in providing such socio-educational models of Korean language programs in the community. Strategies to facilitate such programs in metropolitan cities are briefly suggested.

(The University of New South Wales, UNSW)

핵심어: Korean(한국어), socio-educational(사회교육), motivation(동기), learning-styles (학습 방식), learning experiences(학습 경험) 